\title{
Macrophage-derived Foam Cells Freshly Isolated from Rabbit Atherosclerotic Lesions Degrade Modified Lipoproteins, Promote Oxidation of Low-Density Lipoproteins, and Contain Oxidation-specific Lipid-Protein Adducts
}

Michael E. Rosenfeld, John C. Khoo, Elizabeth Miller, Sampath Parthasarathy, Wulf Palinski, and Joseph L. Witztum Division of Endocrinology and Metabolism, Department of Medicine, University of California San Diego, La Jolla, California $92093-0613$

\begin{abstract}
Pure macrophage-derived foam cells (MFC) were isolated from the aortas of rabbits made atherosclerotic by balloon deendothelialization followed by diet-induced hypercholesterolemia. The MFC were isolated under sterile conditions using an enzymatic digestion procedure and discontinuous density gradient centrifugation. The purity of the MFC preparations was verified immunocytochemically with the macrophage specific monoclonal antibody RAM-11. MFC plated in medium containing $0.5 \%$ FCS for $24 \mathrm{~h}$ contained $\sim 600 \mu \mathrm{g}$ cholesterol per mg cell protein, $\mathbf{8 0 \%}$ of which was esterified cholesterol. The MFC specifically degraded low density lipoprotein (LDL), acetylLDL, copper oxidized LDL, and beta-very low density lipoprotein $(\beta$-VLDL) at rates comparable to mouse peritoneal macrophages (MPM) in 5-h assays. MFC within sections of the atherosclerotic lesions from the ballooned rabbits as well as the MFC isolated from the same lesions in the presence of antioxidants, exhibited positive immunoreactivity with polyclonal guinea pig antisera and mouse monoclonal antibodies directed against malondialdehyde-LDL, and 4-hydroxynonenal-LDL. The MFC also exhibited the capacity to induce the oxidation of LDL at rates comparable to those exhibited by MPM and rabbit aortic endothelial cells. These data provide direct evidence that arterial wall macrophages express modified LDL receptors in vivo, contain epitopes found in oxidized-LDL and are capable of oxidizing LDL even when maximally loaded with cholesterol. (J. Clin. Invest. 1991. 87:90-99.) Key words: macrophages • foam cells • lipoprotein oxidation • scavenger receptors $\bullet$ atherosclerosis $\bullet$ cholesterol-fed rabbits
\end{abstract}

\section{Introduction}

It is now well documented that macrophage-derived foam cells (MFC) ${ }^{1}$ constitute a significant percentage of the cells within atherosclerotic lesions in both humans and most animal mod-

Portions of this study were presented at the 62nd Scientific Sessions of the American Heart Association, 13-16 November 1989.

Address correspondence to Michael E. Rosenfeld. 1990

Received for publication 20 March 1990 and in revised form $10 \mathrm{July}$

1. Abbreviations used in this paper: LDL, low-density lipoprotein; LPDS, lipoprotein-deficient serum; MFC, macrophage-derived foam cells; MPM, mouse peritoneal macrophage; TBARS, thiobarbituric acid reactive substance; WHHL, Watanabe Heritable Hyperlipemic rabbit.

J. Clin. Invest.

(c) The American Society for Clinical Investigation, Inc.

$0021-9738 / 91 / 01 / 0090 / 10 \$ 2.00$

Volume 87, January 1991, 90-99 els (1-8). Because in vitro studies show that macrophages take up native low density lipoproteins (LDL) at rates that are insufficient to induce foam cell formation $(9-11)$ it is still unclear what mechanisms are utilized by the macrophages in vivo for the accumulation of large amounts of cholesteryl esters. Recently, we demonstrated that macrophages within atherosclerotic lesions of the Watanabe Heritable Hyperlipemic rabbit (WHHL) contain immunoreactive oxidation specific lipidprotein adducts (12-15). Although the formation of oxidation products are common cellular reactions, the oxidation specific lipid-protein adducts in atherosclerotic lesions may be derived in whole or in part from oxidized LDL, because LDL with al the properties of in vitro oxidized-LDL can be extracted from the same lesions $(12,13)$.

Macrophages in vitro can also accumulate large amounts of cholesteryl esters when incubated with modified forms of LDL, such as acetyl-LDL and aggregated-LDL and have the capacity to bind and degrade modified lipoproteins, as well as the ability to actually induce the oxidative modification of LDL (9-11, $16,17)$. To determine whether MFC resident within atherosclerotic lesions of cholesterol-fed rabbits contain oxidized epitopes and have properties similar to macrophages studied in vitro, the original methods of Fowler et al. (18-22) were modified to obtain sufficient numbers of pure, sterile MFC to perform the above in vitro assays. In this report we document for the first time the ability of freshly isolated, lipid-filled arterial macrophages to take up and degrade oxidized LDL as well as to effect oxidative modification of LDL. In addition, we also demonstrate that cholesterol feeding leads to the accumulation in rabbit aorta of the epitopes characteristic of oxidized LDL, demonstrated by immunohistology of the whole aorta as well as by immunostaining of the individual isolated arterial foam cells.

\section{Methods}

Isolation of foam cells. To maximize the amount of foam cell-rich atherosclerotic tissue from which to isolate the cells, we removed the endothelial cells of the aorta and left iliac artery of New Zealand White rabbits with a Fogarty embolectomy catheter (4F) and the animals were placed on a high cholesterol diet $(2 \%)$ for $13 \mathrm{wk}(1 \mathrm{wk}$ before the catheterization and $12 \mathrm{wk}$ after the denudation procedure). For each preparation of foam cells, four to six rabbits were sacrificed with a bolus injection of sodium pentobarbital and the entire aorta and left iliac artery were removed and placed in cold HBSS supplemented with glucose, amino acids, and penicillin (100 IU/ml) and streptomycin $(100$ $\mu \mathrm{g} / \mathrm{ml})$.

Under a sterile hood and on ice, the atherosclerotic lesion (intima) was dissected from the remaining media and adventitia and minced. The MFC were released from the minced intima using the enzymatic digestion procedure of Berberian et al. (18). In brief, $1.0 \mathrm{~g}$ of the minced intima was incubated with $10.0 \mathrm{ml}$ HBSS containing 450 units collagenase (type VIIS; Sigma Chemical Co., St. Louis, MO), 4.7 units elastase 
(Sigma Chemical Co.) and $1.0 \mathrm{mg} / \mathrm{ml}$ soybean trypsin inhibitor (Sigma Chemical Co.) for $1 \mathrm{~h}$ at $37^{\circ} \mathrm{C}$. The enzyme/tissue mixture was then filtered through nylon (100- $\mu \mathrm{m}$ mesh) and fresh enzyme cocktail was added to the same minced tissue for an additional $1 \mathrm{~h}$. The released cells were then pelleted at $500 \mathrm{~g}$, resuspended in HBSS containing the glucose and amino acids and purified with a discontinuous density gradient of metrizamide (Sigma Chemical Co.) (30\% cushion, $10 \%$ top, centrifuged at $1,200 \mathrm{~g}$ in a swinging bucket rotor for $15 \mathrm{~min}$ at $10^{\circ} \mathrm{C}$ ). The isolated cells were washed, plated, and maintained in Opti-MEM $I$ reduced serum medium (Gibco, Grand Island, NY) containing $0.5 \%$ FCS overnight. Viability was assessed by the ability of the cells to exclude Trypan blue and averaged $>90 \%$. The plating efficiency of the isolated foam cells was extremely variable, ranging from $<50 \%$ to $>90 \%$ adherence after the overnight incubation. However, many of the most buoyant cells appeared to float in place but were actually firmly attached by means of membrane processes that attached to the plastic. These cells also remained viable as they were capable of excluding Trypan blue throughout the course of the studies.

To assess the purity of the foam cell preparations, we plated the cells on glass coverslips or in chamber slides (Lab Tek, Nunc, Inc., Naperville, IL), fixed with cold methanol for $30 \mathrm{~min}$ and immunostained with the monoclonal antibody RAM-11 (8), which is specific for rabbit macrophages, as well as monoclonal antibody HHF-35 (Enzo Biochem, Inc., New York, NY) (23), which recognizes muscle actin and therefore is specific for smooth muscle cells. All immunostaining procedures were done with an avidin-biotin system conjugated with either horseradish peroxidase or alkaline phosphatase (Vector Laboratories, Inc., Burlingame, CA). All experimental procedures with rabbits were conducted under a protocol approved by the Animal Care and Use Committee of the University of California San Diego.

Detection of oxidized lipid-protein adducts. To determine whether the atherosclerotic lesions in the ballooned, cholesterol-fed rabbits as well as the MFC isolated from the same lesions, contained oxidationspecific lipid-protein adducts, we fixed small segments of the abdominal aorta in formal sucrose containing $50 \mu \mathrm{M}$ butylated hydroxytoluene (BHT) and embedded in paraffin. Serial 5-8- $\mu \mathrm{m}$-thick sections were cut from the segments of aorta and immunostained using a panel of recently described antibodies specific for epitopes characteristic of those generated during the oxidative modification of LDL (12-15). Antibodies utilized included $(a)$ guinea pig polyclonal antiserum MAL2 and the mouse monoclonal antibody MDA-2, both generated against autologous malondialdehyde-conjugated LDL (MDA-LDL) and (b) guinea pig polyclonal antiserum HNE-7 and mouse monoclonal antibody NA59 generated against 4-hydroxynonenal-conjugated LDL (4HNE-LDL) and (c) mouse monoclonal antibody OLF4-3C10, generated against fragments of apoprotein $\mathrm{B}$ resulting from the $\mathrm{Cu}^{++}$oxidation of LDL (12-15). Additional sections were stained with nonspecific sera (goat or horse). In addition, MFC isolated and cultured on chamber slides in the presence of BHT, were fixed with methanol and immunostained as above.

Lipoprotein degradation assays. MPM were elicited by intraperitoneal injection of $2 \mathrm{ml}$ thioglycollate medium (Difco Laboratories, Detroit, MI) $3 \mathrm{~d}$ before harvesting. The macrophages were plated in 24well clustered dishes at a density of $1 \times 10^{6}$ cells/well in RPMI 1640 medium containing $10 \%$ FCS. After $2 \mathrm{~h}$, nonadherent cells were removed and the cells washed with PBS. To maximize the number of LDL receptors, we incubated the cells overnight in RPMI 1640 containing $5 \mathrm{mg} / \mathrm{ml}$ lipoprotein-deficient serum (LPDS). The rabbit arterial foam cells were plated at $5 \times 10^{5}$ cells/well in Opti-MEM I containing $0.5 \%$ FCS. Nonadherent cells were removed after an overnight incubation and before the addition of the labeled lipoproteins.

LDL $(d=1.019-1.063)$ and LPDS $(d>1.215)$ were isolated by preparative ultracentrifugation from fresh human plasma using antioxidants and protease inhibitors as described $(12,13)$. The lipoproteins were dialyzed extensively against PBS containing $0.01 \%$ EDTA ( $\mathrm{pH}$ 7.4). $\beta$-VLDL, $(d<1.006)$ was isolated by preparative ultracentrifugation from the plasma of cholesterol-fed rabbits. Acetyl-LDL was prepared according to the method of Basu et al. (24), and copper $\left(\mathrm{Cu}^{++}\right)$ oxidized LDL was prepared as described by Steinbrecher et al. (25). Modification of the lipoproteins was checked by agarose electrophoresis, thiobarbituric acid reactive substance (TBARS) reactivity and enhanced uptake in MPM compared to native LDL. Lipoproteins were radioiodinated with carrier-free sodium ${ }^{125}$ I-iodide (Amersham Corp., Arlington Heights, IL) by the method of Salacinski et al. (26) using the solid-phase oxidizing agent, Iodogen (Pierce Chemical Co., Rockford, IL). Specific activities varied from 50-400 CPM/mg of LDL protein. The degradation of ${ }^{125} \mathrm{I}-\mathrm{LDL},{ }^{125} \mathrm{I}$-acetyl-LDL, ${ }^{125} \mathrm{I}-\beta$-VLDL, ${ }^{125} \mathrm{I}-$ $\mathrm{Cu}^{++}$-oxidized $\mathrm{LDL}$ was determined as described by Goldstein et al. (27). Each cell monolayer received $0.5 \mathrm{ml}$ Opti-MEM medium containing $0.5 \%$ FCS and the indicated concentration of labeled lipoprotein. To determine nonspecific degradation, unlabeled lipoprotein, at a concentration 25 times that of the labeled lipoprotein, was added to each well. After incubation at $37^{\circ} \mathrm{C}$ for $5 \mathrm{~h}$, the medium was removed and the amount of ${ }^{125}$ I-labeled TCA soluble (noniodide) material was determined.

Determination of cellular cholesterol content. The monolayers of cells used in the degradation assays were washed with PBS, and solubilized in $0.25 \mathrm{ml}$ of $0.2 \mathrm{M} \mathrm{NaOH}$. Aliquots were removed for gamma counting and for protein determination by the method of Lowry et al. (28). Before reading the optical density, we added $2 \mathrm{ml}$ of chloroform to extract the lipids. The chloroform fraction was assayed for total and free cholesterol according to the enzymatic method of Gamble et al. (29). In order to compare the cholesterol content of the isolated MFC with that of MPM maximally loaded with acetyl-LDL, the MPM were incubated with $100 \mu \mathrm{g} / \mathrm{ml}$ acetyl-LDL for $3 \mathrm{~d}$ and refed for an additional $3 \mathrm{~d}$. The mouse cells were then treated identically to the MFC as described above.

Analysis of the capacity to induce LDL oxidation. For the measurement of the capacity to oxidize LDL the rabbit arterial MFC were plated at $5 \times 10^{5}$ cells/dish in $35-\mathrm{mm}$ culture dishes in RPMI medium containing $0.5 \%$ FCS. Resident MPM were obtained via lavage, and were plated at a density of $2.5 \times 10^{6}$ cells/dish (this excess of cells yields a continuous monolayer after an overnight incubation). Confluent cultures of rabbit aortic endothelial cells (EC) (in 60-mm dishes) were also used as positive controls (25). After the overnight incubation, the medium containing any nonadherent cells was removed and the cells were incubated at $37^{\circ} \mathrm{C}$ with $2 \mathrm{ml}$ of Ham's F-10 medium containing $200 \mu \mathrm{g}$ of ${ }^{125} \mathrm{I}$-LDL for $24 \mathrm{~h}$. The medium was then analyzed for TBARS after the method of Patton and Kurtz (30). An aliquot containing $5 \mu \mathrm{g}$ of the ${ }^{125}$ I-LDL that had been incubated with the cells was tested for degradation using a fresh culture of resident MPM as described above.

\section{Results}

Yield and purity of the isolated foam cell preparations. To maximize the yield of isolated MFC, the rabbits were subjected to Fogarty balloon denudation of the endothelial lining of their aortas $1 \mathrm{wk}$ after placing the animals on a high-cholesterol diet (2\%). The combination of removal of the endothelium and a marked hypercholesterolemia (plasma cholesterol levels $>1,000 \mathrm{mg} / \mathrm{dl}$ during the $12 \mathrm{wk}$ before sacrifice) yielded lesions that consisted almost entirely of MFC. This is demonstrated in Fig. 1, where serial sections of the abdominal aorta of one of the animals have been immunostained with antibodies specific for macrophages or smooth muscle cells.

By starting with atherosclerotic tissue that contained very few smooth muscle cells, and using discontinuous density gradient centrifugation to separate the isolated cells on the basis of size and buoyant density, we obtained cultures of pure MFC that exhibited no contamination with smooth muscle cells. The final yield was generally between $1-2 \times 10^{6}$ pure MFC per gram of aorta. Fig. 2 demonstrates that the majority of the isolated cells were large, round, and intact (excluded Trypan 

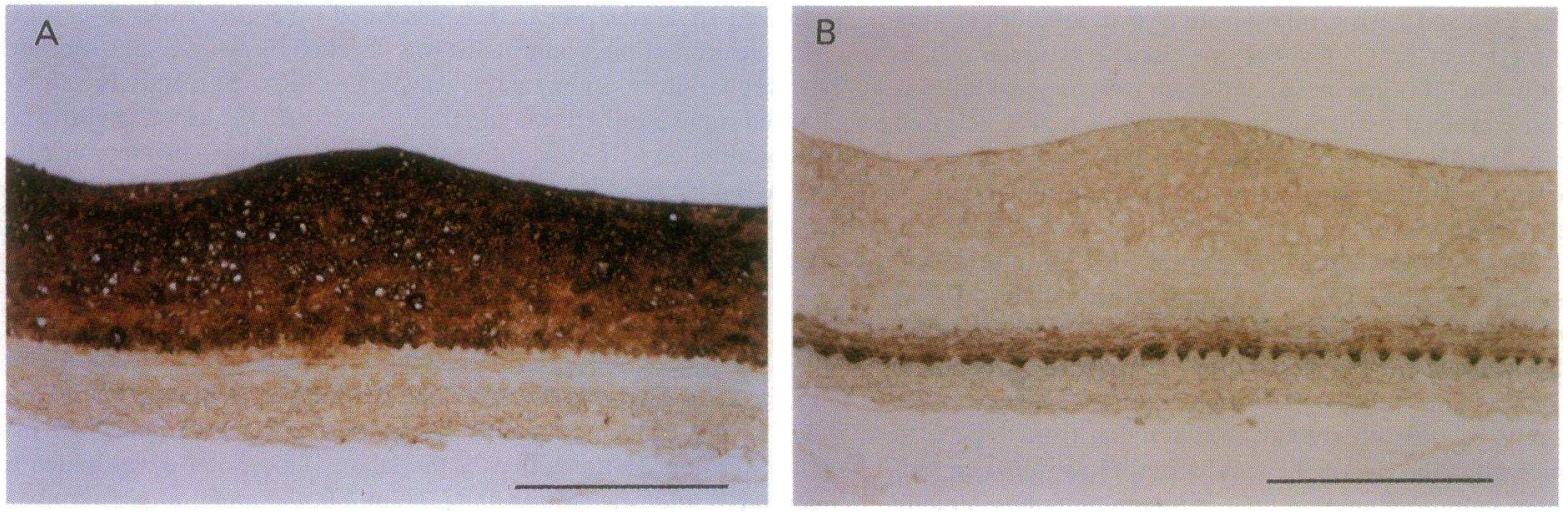

Figure 1
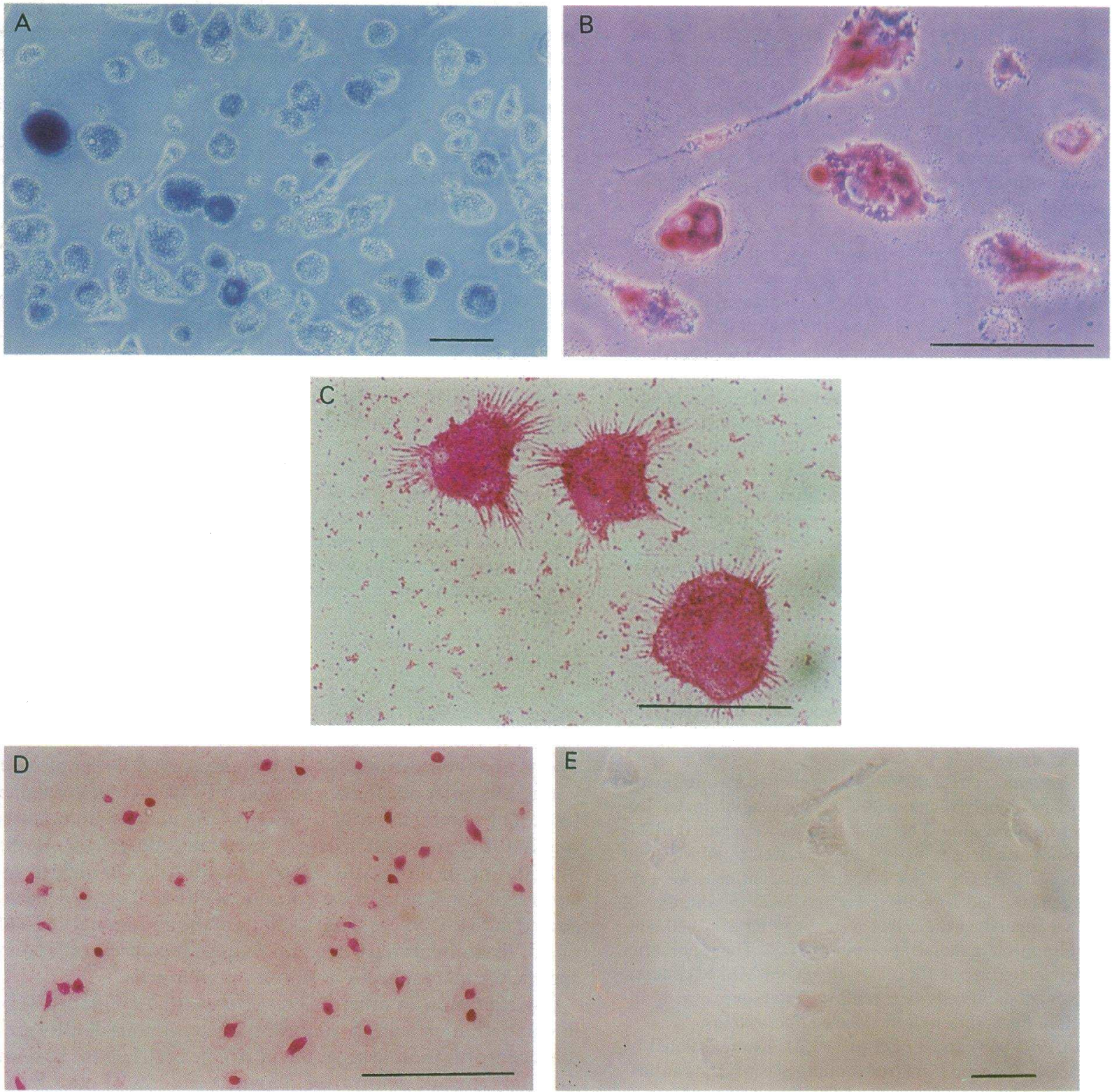

Figure 2 


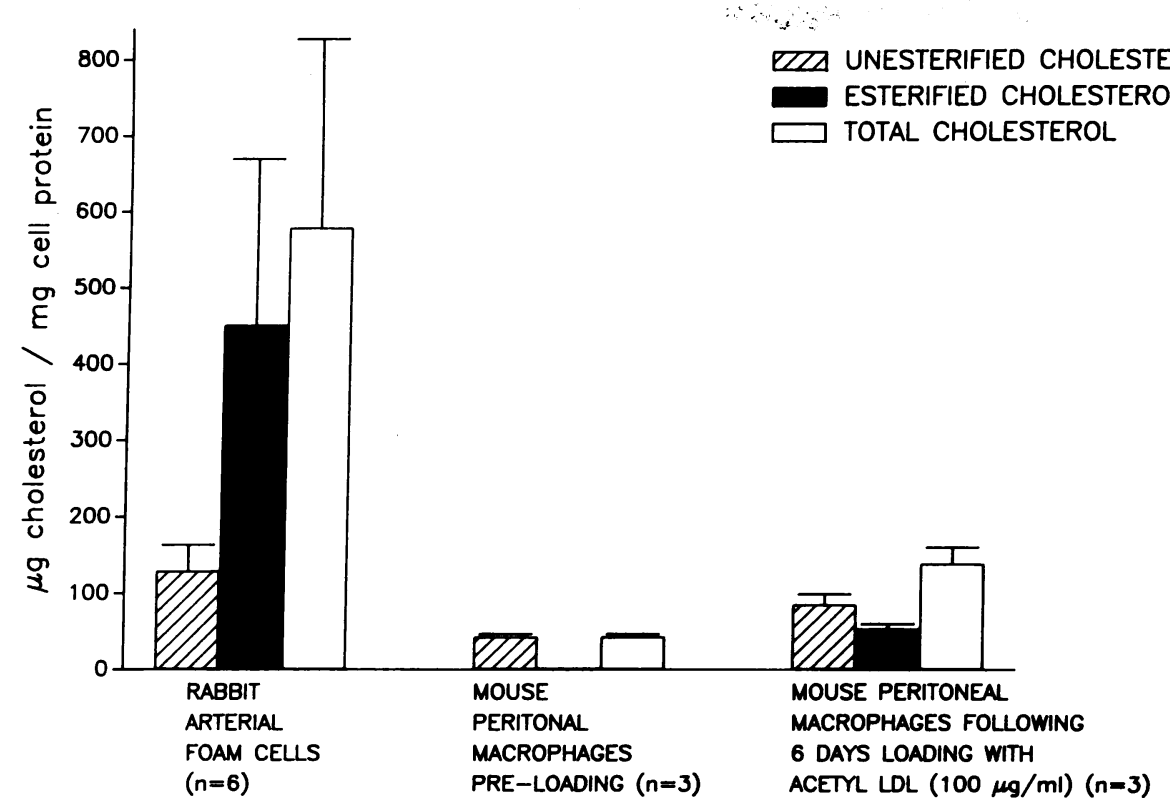

Figure 3. Comparison of the cholesterol content of isolated rabbit arterial foam cells and in vitro loaded mouse peritoneal macrophages. The cholesterol content was determined as described under Methods. Values shown are the means \pm SD. $n$, number of separate experiments where each experiment yielded an average of triplicate wells.

blue) and adherent to the plastic (Fig. $2 A$ ). They contained massive amounts of neutral lipid, as shown with Oil Red $O$ staining (Fig. $2 B$ ), and consisted of cells that were immunoreactive only with the macrophage-specific antibody RAM-11 (Fig. 2, $C$ and $D$ ), and not with the smooth muscle specific antibody HHF-35 (Fig. $2 E$ ).

Cholesterol content of the isolated foam cells. Fig. 3 demonstrates that the isolated MFC contained massive amounts of cholesterol ( $\sim 600 \mu \mathrm{g} / \mathrm{mg}$ cell protein) that was predominantly esterified cholesterol ( $>80 \%$ of the total cholesterol). In contrast, when MPM were fed acetyl-LDL for up to $6 \mathrm{~d}$, the amount of cholesterol accumulated by the cells was considerably less than that in the arterial macrophages in vivo. In addition, it appeared that a smaller percentage of the total cholesterol which accumulated in the MPM was stored as esterified cholesterol.

Presence of oxidation specific lipid-protein adducts. To determine whether the isolated MFC and the atherosclerotic lesions induced by the combination of ballooning and cholesterol feeding contain oxidation-specific lipid-protein adducts, such as have been previously demonstrated in atherosclerotic lesions from the WHHL rabbit $(12,13,15,31,32)$, we immunostained isolated foam cells as well as serial sections of the lesions with a panel of both polyclonal and monoclonal antibodies that recognize MDA- and 4-HNE-lysine adducts and oxidation specific apoprotein B fragments (OLF4-3C10). Fig. 4 shows that the atherosclerotic lesions from which the MFC were subsequently isolated contained macrophages which stained with all of the antibodies tested. Fig. 5 demonstrates that the isolated MFC still retained their immunoreactivity with several of the oxidation-specific antibodies and exhibited the same type of punctate and annular staining patterns we have previously observed in macrophages in vivo $(12,15)$. The immunostaining shown in both Figs. 4 and 5 was specific as the use of nonspecific sera (goat or horse) (Figs. $4 K$ and $5 E$ ) yielded sections devoid of staining.

Capacity to degrade $L D L$, acetyl- $L D L$, oxidized $L D L$, and $\beta-V L D L$. Fig. 6 demonstrates that the isolated MFC degraded very little native $L D L$, but were capable of degrading considerable amounts of acetyl-LDL, $\mathrm{Cu}^{++}$oxidized $\mathrm{LDL}$, and $\beta$ VLDL in 5-h assays. The degradation of these ligands is highly specific as the addition of 25-fold excess of the unlabeled ligands reduced the amounts of degradation products by 60 $90 \%$. In comparison, MPM also degraded very little native $\mathrm{LDL}$, and comparable amounts of acetyl- $\mathrm{LDL}, \mathrm{Cu}^{++}$oxidized LDL and $\beta$-VLDL.

Capacity to oxidize $L D L$. Table I shows the results of two separate experiments comparing the ability of MFC and other cell types to oxidize LDL. Although plated at a considerably lower density than the other cell types $\left(5 \times 10^{5}\right.$ vs. $\left.2.5 \times 10^{6}\right)$,

Figure 1. Starting material for cell isolation. Immunocytochemical analysis using the avidin-biotin-horseradish-peroxidase technique showing the cellular composition of the atherosclerotic lesion that develops in the aorta of New Zealand White rabbits after balloon denudation of the endothelium and $12 \mathrm{wk}$ of hypercholesterolemia. $A$ demonstrates that the majority of this lesion in the abdominal aorta is comprised of macrophages that are immunoreactive with monoclonal antibody RAM-11, specific for rabbit macrophages. $B$ shows the absence of smooth muscle cells in a serial section of the same lesion as determined with the monoclonal antibody HHF-35 which recognizes muscle actins. Final magnification of $A$ and $B: 220$. Bars, $100 \mu \mathrm{m}$.

Figure 2. Isolated foam cells in culture. Photomicrographs of isolated rabbit arterial macrophage-derived foam cells after overnight incubation in culture. $A$ is a phase contrast micrograph showing how the cells adhere and spread on tissue culture plastic and exclude Trypan blue. Final magnification of $A: 890$; bar, $10 \mu \mathrm{m}$. (B) The high neutral lipid content of the foam cells as determined with Oil Red $O$ staining. Phase contrast. Final magnification of $B: 2,200$; bar, $10 \mu \mathrm{m}$. $(C)$ The positive immunoreactivity of the isolated cells with RAM-11. Avidin-biotin-alkaline phosphatase, final magnification of $C: 2,200 ;$ bar, $10 \mu \mathrm{m}$. $(D)$ The RAM-11 positive macrophages at lower magnification: $220 ;$ bar, $100 \mu \mathrm{m}$. $(E)$ Negative immunoreactivity of the isolated cells with HHF-35. Avidin-biotin-alkaline phosphatase. Final magnification: 890 ; bar, $10 \mu \mathrm{m}$. 

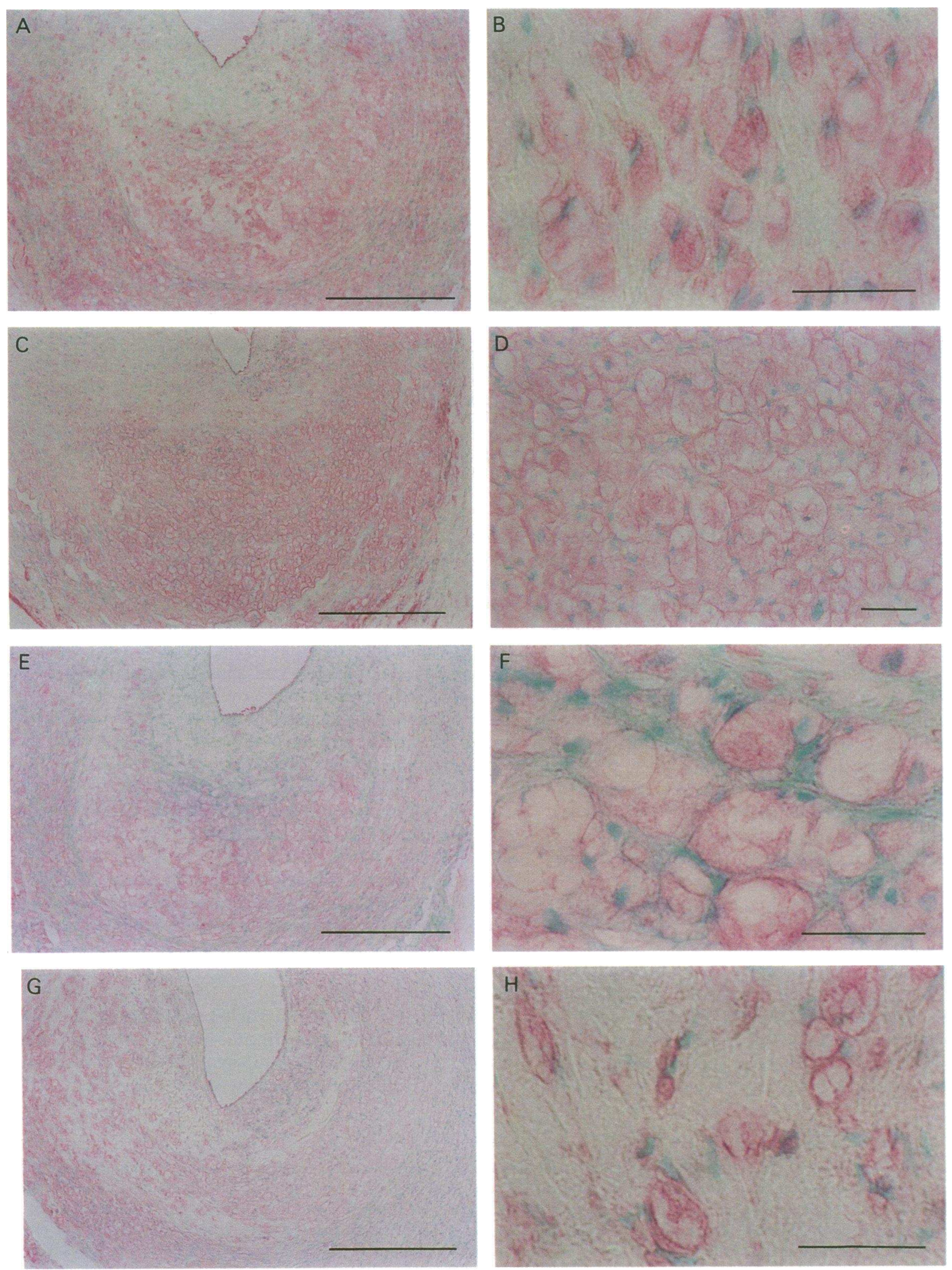

Figure 4. Macrophages within atherosclerotic lesions from ballooned, cholesterol-fed rabbits contain oxidation specific lipid-protein adducts. Immunocytochemical staining of sections of the abdominal aorta containing atherosclerotic lesions, with antibodies generated against malondialdehyde conjugated LDL (Mal-2 and MDA-2), 4-hydroxynonenal conjugated LDL (HNE-7), $\mathrm{Cu}^{++}$oxidized LDL (OLF4-3C10), macrophages (RAM-11), and smooth muscle cells (HHF-35). ( $A$ and $B$ ) Guinea pig polyserum Mal-2. $(C$ and $D)$ Mouse monoclonal antibody MDA-2. $(E$ and $F$ ) Guinea pig polyserum HNE-7. $(G$ and $H$ ) Mouse monoclonal antibody OLF4-3C10. (I) RAM-11. (J) HHF-35. (K) Nonspecific (goat) serum. The final magnification of panels $A, C, E, G, I-K: 220$; bars, $100 \mu \mathrm{m}$. $(B, F, H)$ Magnification 2,200; bars, $10 \mu \mathrm{m}$. (D) Magnification 890; bar, $10 \mu \mathrm{m}$. All staining utilized an avidin-biotin-alkaline phosphatase procedure as described in Methods. 

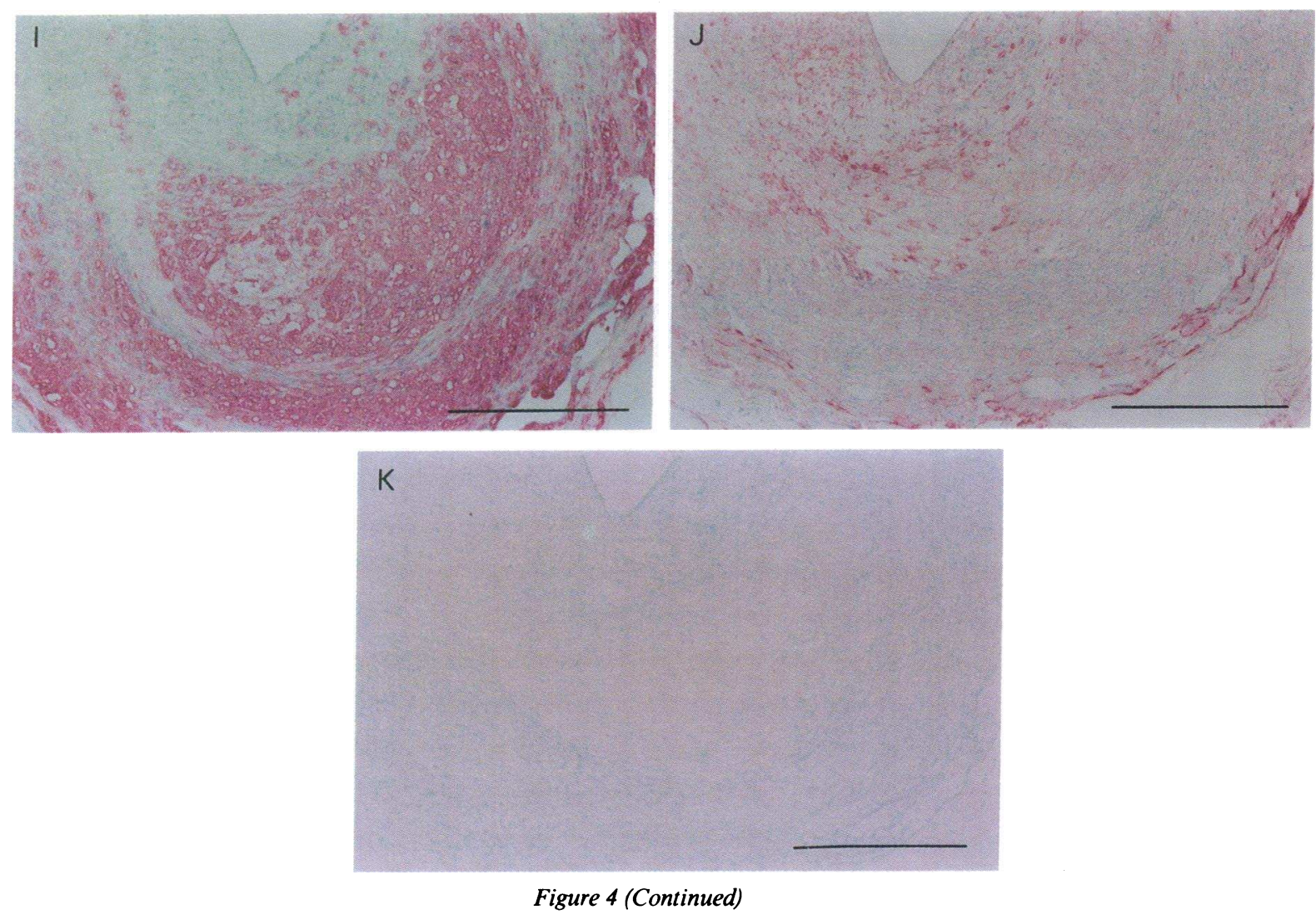

the isolated MFC were still capable of inducing comparable amounts of LDL lipid peroxidation as the MPM and the rabbit aortic EC. In addition, the LDL that was oxidized by the MFC was recognized and degraded by MPM at a rate comparable to that observed with LDL incubated with the MPM or rabbit EC.

\section{Discussion}

These studies have demonstrated for the first time that cholesteryl-ester rich MFC freshly isolated from atherosclerotic rabbit aorta have the capacity to degrade oxidized LDL, and retain the capacity to oxidize LDL. Further, the demonstration that the MFC and the atherosclerotic lesions from which they were isolated, contain oxidation-specific lipid-protein adducts, is the first indication that lipoprotein oxidation may also occur in cholesterol fed animals analogous to that reported in WHHL rabbit aortas $(12,13,15,31,32)$.

There have been several different approaches to the isolation of foam cells from the artery wall. Primary cultures of arterial cells that have migrated out of tissue explants have been previously used to demonstrate the existence of arterial foam cells with characteristics similar to macrophages (33). However, this study did not look at parameters associated with lipoprotein metabolism. The capacity of rabbit foam cells to bind and accumulate $\beta$-VLDL, and acetyl-LDL was first ascertained also using explant techniques $(34,35)$. More recently, the same activity was demonstrated in cells that had been isolated by enzymatic digestion from human lesions and grown in culture for up to 2 wk (36). However, all three of these latter studies focused only on the qualitative demonstration of the uptake of fluorescently labeled lipoproteins.

The yield of cells using explant or seeding techniques is generally insufficient to perform quantitative in vitro assays, and there is a significant waiting period for the establishment of the cultures (up to $2 \mathrm{wk}$ ), a time during which specific receptors may be induced or down-regulated and phenotypic modulation may occur (37). Further, the resulting cultures are of mixed cell types when atherosclerotic tissue is used as the source of the explants.

Arterial foam cells can also be isolated using enzymatic digestion and gradient centrifugation procedures (19-22, 38). These techniques have previously been used to demonstrate the presence of foam cells exhibiting characteristics of macrophages $(19,21)$, to study the enzyme profiles and distribution of lipids within intracellular organelles $(20,22)$, and the capacity of the different arterial cells for synthesizing prostaglandins $(22,38)$. Once again, none of the studies cited looked at lipoprotein-cell interactions.

The advantages of this combined enzymatic and gradient centrifugation approach are the much greater yield of isolated cells, and the speed at which cells can be obtained (hours), and the purity of the resulting cell populations. The yield of pure foam cells in the current studies $\left(1-2 \times 10^{6}\right.$ cells per gram or $\sim 5-10 \times 10^{6}$ cells per experiment) has allowed us to study the capacity of purified arterial macrophage-derived foam cells to metabolize modified lipoproteins using quantitative in vitro binding and degradation techniques. The speed at which we isolate and plate the cells (maximum of $24 \mathrm{~h}$ from the time of sacrifice to the time of utilization) should minimize induction 

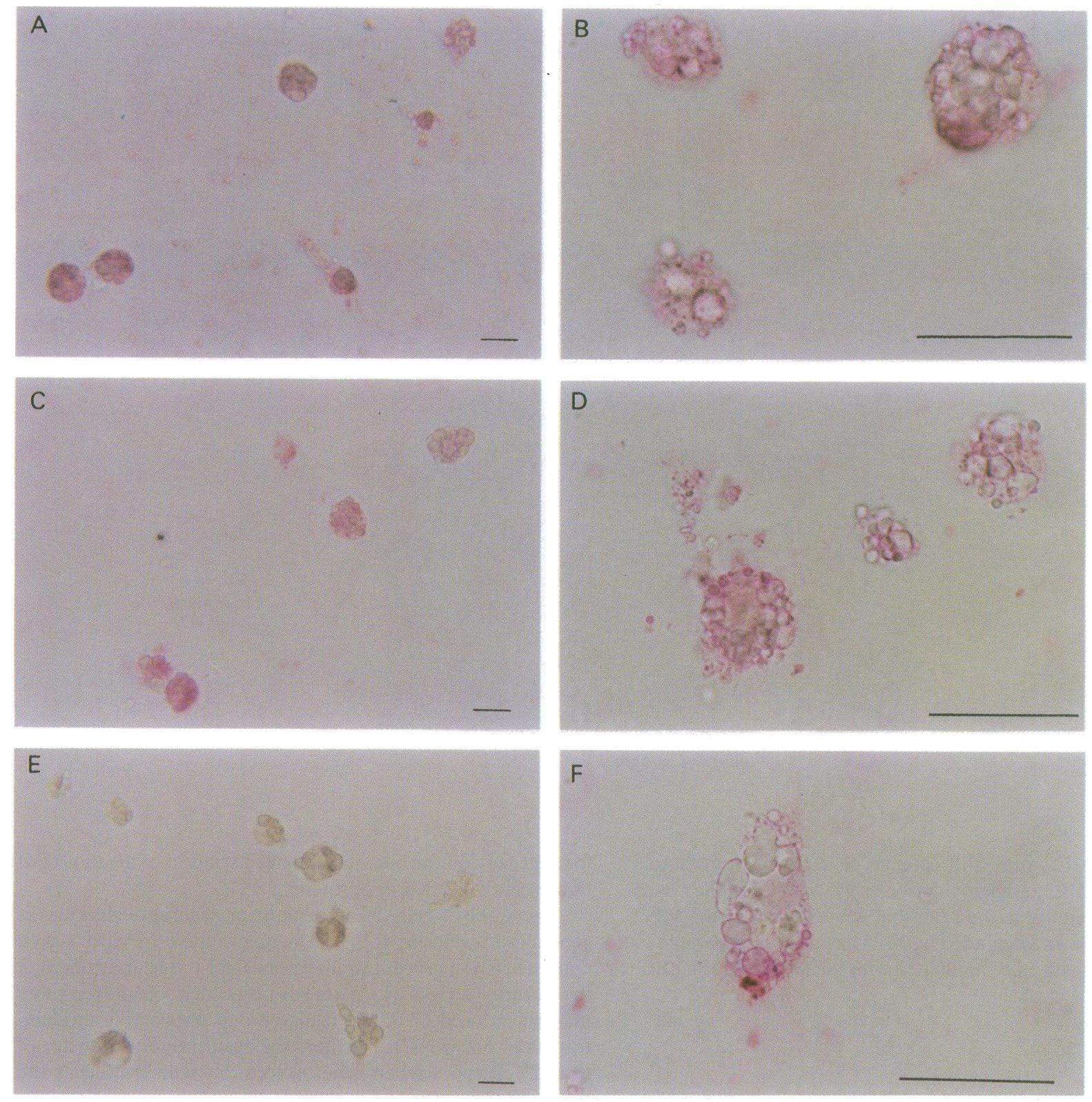

Figure 5. Isolated foam cells contain oxidation specific lipid-protein adducts. Immuncytochemical staining of the isolated foam cells with monoclonal antibodies generated against malondialdehyde conjugated LDL and 4-hydroxynonenal conjugated LDL. $(A$ and $B)$ Mouse monoclonal antibody MDA-2. $(C, D, F)$ Mouse monoclonal antibody NA59. (E) Nonspecific (goat) serum. The final magnification of $A$, $C$, and $E$ : 440; bars, $10 \mu \mathrm{m}$. Final magnification of $B, D$, and $F: 2,200 ;$ bars, $10 \mu \mathrm{m}$. All staining utilized an avidin-biotin-alkaline phosphatase procedure as described in Methods.

of receptor expression compared to previously used procedures which required more extensive time in culture. Thus, the activity exhibited by the isolated cells may be more reflective of their capacities in vivo.

However, by using digestive enzymes, there is always the question as to whether the enzymes may have damaged or altered the surface properties of the isolated cells. Fowler et al. (35) demonstrated that foam cells isolated using collagenase and elastase retain $\mathrm{Fc}$ and $\mathrm{C} 3$ receptors on their membranes and are capable of phagocytosing IgG coated, Fc-bound erythrocytes. The present studies have further demonstrated that the enzymatic digestion procedure did not compromise the capacity of isolated MFC to specifically bind and degrade lipopro- teins, indicating that the LDL receptor, that form of the LDL receptor that specifically binds $\beta$-VLDL (39), and the scavenger receptors, (including the putative oxidized-LDL receptor [40]) were still expressed after enzymatic digestion and 18-24 h in culture.

An additional advantage to studying MFC is their content of cholesterol. It is clear from the data presented in Fig. 3, that attempts to load MPM with acetyl-LDL over a 6-d period did not yield cells with a comparable content or distribution of cholesterol. Loading with acetyl-LDL does not lead to storage of an equivalent percentage of cholesteryl ester as is observed with the isolated MFC. Thus, it is possible that a higher content of free cholesterol in the in vitro systems may yield different 


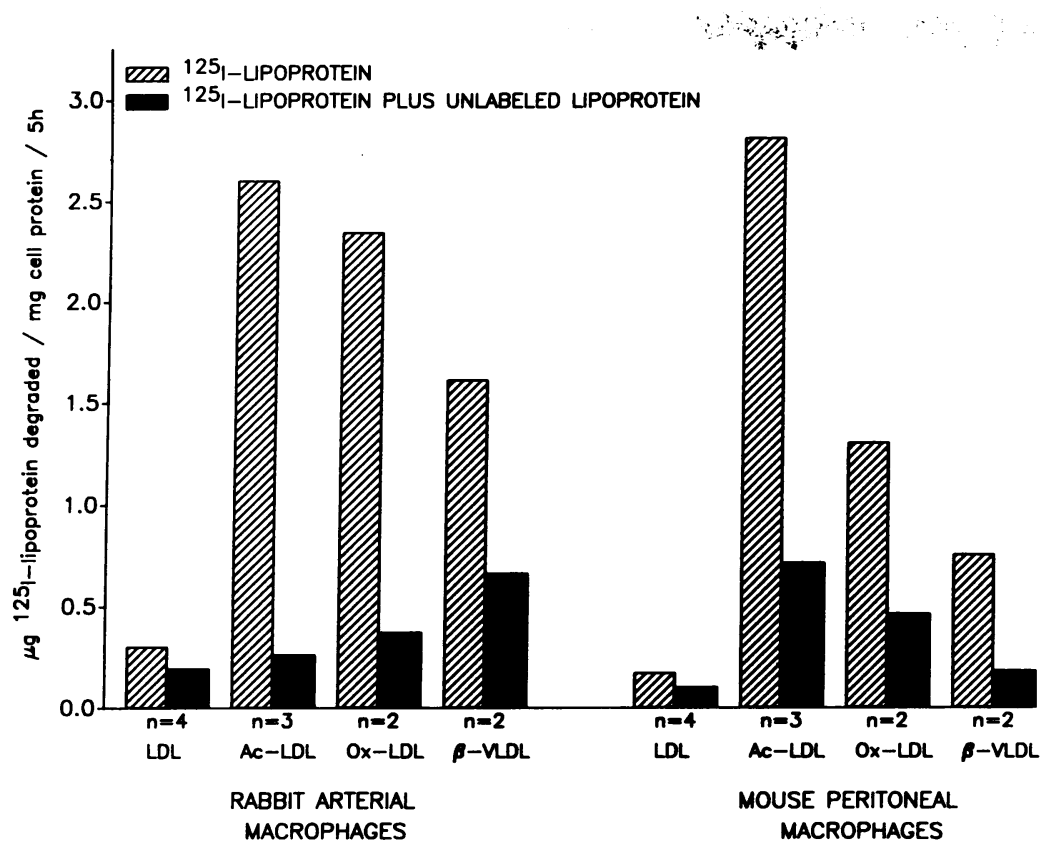

Figure 6. Comparison of the capacity to degrade LDL, modified forms of LDL, and $\beta$-VLDL by isolated rabbit arterial foam cells and mouse peritoneal macrophages. Monolayers of adherent cells were incubated with $10 \mu \mathrm{g}$ protein $/ \mathrm{ml}$ of LDL, acetyl-LDL (Ac-LDL), $\mathrm{Cu}^{++}$oxidized LDL (Ox-LDL) and $\beta$ VLDL in the absence and presence of 25 -fold unlabeled lipoproteins for $5 \mathrm{~h}$ at $37^{\circ} \mathrm{C}$. Degradation products were determined in the media as described under Methods. $n$, number of separate experiments. Values shown are the means of $n$ experiments where each experiment yielded an average of duplicate wells. information about the effects of lipoprotein derived cholesterol (stored predominantly as cholesteryl-esters in vivo) on a variety of cellular functions (41).

Clearly, cellular functions such as the capacity for binding and degrading modified lipoproteins and the ability to oxidize LDL do not appear to be compromised by the intracellular accumulation of even large amounts of esterified cholesterol. As shown in Fig. 6, the MFC can still bind and degrade small amounts of LDL, and larger amounts of acetyl-LDL, oxidizedLDL, and $\beta$-VLDL in short term assays. Thus, the present in vivo observations are consistent with previous studies of foam cells derived from explanted atherosclerotic lesions (30-32). The present studies specifically document that oxidized LDL is taken up and degraded by arterial foam cells and provides

Table I. Comparison of the Capacity of Different Cell Types to Oxidize $L D L$ and the Degradation of the Oxidized-LDL by Mouse Peritoneal Macrophages

\begin{tabular}{|c|c|c|c|c|}
\hline \multirow{2}{*}{ - } & \multicolumn{2}{|c|}{ Oxidation } & \multicolumn{2}{|c|}{ Degradation } \\
\hline & Exp. 1 & Exp. 2 & Exp. 1 & Exp. 2 \\
\hline & \multicolumn{2}{|c|}{$\begin{array}{c}\text { nmol MDA/mg } \\
L D L \text { protein }\end{array}$} & \multicolumn{2}{|c|}{$\mu \mathrm{g} / \mathrm{mg}$ cell protein } \\
\hline Native LDL (cell free) & 0.3 & 2.7 & 0.4 & 0.3 \\
\hline Rabbit endothelial cells & 44 & 45 & 5.4 & 7.3 \\
\hline Mouse peritoneal $\mathbf{M} \phi$ & 56 & 53 & 5.9 & 5.8 \\
\hline Isolated foam cells & 42 & 38 & 6.6 & 3.5 \\
\hline
\end{tabular}

Monolayers of cells were incubated with $200 \mu \mathrm{g} / \mathrm{ml}$ of human ${ }^{125} \mathrm{I}$ LDL in Ham's F-10 medium for $24 \mathrm{~h}$ at $37^{\circ} \mathrm{C}$. The medium was then analyzed for TBARS activity as described under Methods. $5 \mu \mathrm{g}$ of the ${ }^{125}$ I-LDL that had been incubated with the cells was added to fresh MPM and degradation products were measured as described in Methods. Values shown are the average of triplicate wells except for isolated foam cells where values are the average of duplicate wells. All cell types were plated at $2.5 \times 10^{6}$ cells/well except for isolated foam cells where cells were plated at $5 \times 10^{5}$ cells/well. quantification of lipoprotein degradation whereas previous studies were purely descriptive. The results from the present studies are also consistent with in vitro observations that the acetyl-LDL receptor and $L D L / \beta$-VLDL receptors are expressed by macrophages $(9,10)$ and are not down-regulated by cholesterol loading (10).

Because the MFC retain their capacity to induce the oxidation of LDL (Table I) and $\beta$-VLDL (data not shown) and contain immunoreactive oxidation specific lipid-protein adducts (Fig. 5), some of the accumulated lipoprotein-derived lipid may be stored in an oxidized form. This would be consistent with recent in vitro observations of Sparrow et al. (40) that oxidized-LDL appears to accumulate within macrophages in an undegraded form. The retention of oxidized lipoproteins may have an impact on the long-term capacity of the cells to further degrade native or modified lipoproteins (42).

The direct comparison of the capacity of several different cell types to oxidize LDL is somewhat misleading (Table I). Although the MFC were plated at $20 \%$ of the density of the MPM or EC, they were still able to effect as much lipid peroxidation in the LDL present in the medium as the other cell types when the data were expressed as the amount of MDA produced per milligram of LDL added. If the activity was normalized on the basis of cell protein, it would appear that the MFC may have greater capacity for oxidizing LDL than the other cell types. However, because the continuous accumulation of oxidized-LDL may be toxic to the cells (43) it would be necessary to determine the rate of loss of cells during the incubation period. At present, the low yield of foam cells does not allow us to make this type of measurement, although it would be of interest to determine whether the large amount of lipid stored within the MFC make them more or less resistant to the cytotoxic effects of oxidized LDL.

The presence of immunoreactive oxidation-specific lipidprotein adducts in both the atherosclerotic lesion and in the isolated MFC from the cholesterol-fed rabbits indicates that the cells contained the epitopes in vivo and that the oxidation did not occur during the isolation procedure. Although the antibod- 
ies used in this study were generated against oxidized-LDL, they are not specific for lipid-protein adducts derived entirely from lipoproteins, i.e., they recognize MDA-lysine residues present on a variety of different proteins (14). However, almost certainly some of the lipid-protein adducts recognized by the antibodies in atherosclerotic lesions and specifically in macrophages, are of lipoprotein origin because $(a)$ macrophages in other organs, such as spleen and liver, do not stain with these antibodies, nor does normal aortic tissue, (b) LDL can be gently extracted from the same lesions that contain apo $B$ and apo $B$ fragments that are immunoreactive to the same antibodies $(12,13)$, and $(c)$ we have consistently observed an inverse relationship between the distribution of immunoreactive apoprotein B and oxidized epitopes in areas of lesions containing macrophages $(15,31)$. This suggests that the macrophages may effect the oxidation of LDL followed by the rapid uptake and further degradation of the apoprotein component. The present observations of macrophage associated oxidation-specific lipid-protein adducts are consistent with our earlier studies of the distribution of oxidation specific lipid-protein adducts in atherosclerotic lesions from the WHHL rabbits (15). Those studies demonstrated punctate and annular intracellular staining patterns in macrophage-derived foam cells within both fatty streaks and more advanced lesions. The present observations indicate that the oxidative process may not be limited to lesions derived from a predominantly LDL hypercholesterolemia as occurs in the WHHL rabbit. Cholesterol feeding of rabbits results predominantly in the elevation of $\beta$-VLDL and our results clearly document that there is a marked accumulation in the aorta of oxidation specific lipid-protein adducts. This is consistent with the studies of Parthasarathy et al. which have shown that oxidation of $\beta$-VLDL enhances its uptake in macrophages (42). Thus, oxidation of lipoproteins may be a generalized phenomenon underlying the formation of macrophage-derived foam cells.

\section{Acknowledgments}

The authors would like to thank Michael Burson and Paula Sicurello for their excellent technical contributions and Dr. Daniel Steinberg for help in the interpretation of the data and the writing of this manuscript.

This work was supported in part by National Institutes of Health grants HL42617 and HL14197 and HL-34724.

\section{References}

1. Gown, A. M., T. Tsukada, and R. Ross. 1986. Human atherosclerosis. II. Immunocytochemical analysis of the cellular composition of human atherosclerotic lesions. Am. J. Pathol. 125:191-207.

2. Munro, J. M., J. D. Van Der Walt, and C. S. Munro. 1987. An immunohistochemical analysis of human aortic fatty streaks. Hum. Pathol. 18:375-380.

3. Gerrity, R. G. 1981. The role of the monocyte in atherogenesis. I. Transition of blood-borne monocytes into foam cells in fatty lesions. Am. J. Pathol. 103:181-190.

4. Scott, R. F., D. N. Kim, J. Schmee, and W. A. Thomas. 1986. Atherosclerotic lesions in coronary arteries of hyperlipidemic swine. 2. Endothelial cell kinetics and leukocyte adherence associated with early lesions. Atherosclerosis 62:1-10.

5. Joris, I., T. Zand, J. J. Nunnari, F. J. Krolikowski, and G. Majno. 1983. Studies on the pathogenesis of atherosclerosis. I. Adhesion and emigration of mononuclear cells in aorta of hypercholesterolemic rats. Am. J. Pathol. 113:341358.

6. Faggiotto, A., R. Ross, and L. Harker. 1984. Studies of hypercholesterolemia in the nonhuman primate. I. Changes that lead to fatty streak formation. Arteriosclerosis. 4:323-340.

7. Rosenfeld, M. E., T. Tsukada, A. M. Gown, and R. Ross. 1987. Fatty streak initiation in Watanabe heritable hyperlipemic and comparably hypercholesterolemic fat-fed rabbits. Arteriosclerosis. 7:9-23.

8. Tsukada, T., M. E. Rosenfeld, R. Ross, and A. M. Gown. 1986. Immunocytochemical analysis of cellular components in atherosclerotic lesions. Use of monoclonal antibodies with the Watanabe and fat-fed rabbits. Arteriosclerosis. 6:601-613.

9. Goldstein, J. L., Y. K. Ho, S. K. Basu, and M. S. Brown. 1979. Binding site on macrophages that mediates uptake and degradation of acetylated low density lipoproteins producing massive cholesterol deposition. Proc. Natl. Acad. Sci. USA. 76:333-337.

10. Fogelman, A. M., M. E. Haberland, J. Seager, M. Hokom, and P. A. Edwards. 1981. Factors regulating the activities of the low density lipoprotein receptor and the scavenger receptor on human monocytes-macrophages. J. Lipid Res. 22:1131-1141.

11. Steinberg, D., S. Parthasarathy, T. E. Carew, J. C. Khoo, and J. L. Witztum. 1989. Beyond cholesterol: modifications of low-density lipoprotein that increase its atherogenicity. N. Engl. J. Med. 320:915-924.

12. Palinski, W., M. E. Rosenfeld, S. Ylä-Herttuala, G. C. Gurtner, S. A. Socher, S. W. Butler, S. Parthasarathy, T. E. Carew, D. Steinberg, and J. L. Witztum. 1989. Low density lipoprotein undergoes oxidative modification in vivo. Proc. Natl. Acad. Sci. USA. 86:1372-1376.

13. Ylä-Herttuala, S., W. Palinski, M. E. Rosenfeld, S. Parthasarathy, T. E. Carew, S. Butler, J. L. Witztum, and D. Steinberg. 1989. Evidence for the presence of oxidatively modified low density lipoprotein in atherosclerotic lesions of rabbit and man. J. Clin. Invest. 84:1086-1095.

14. Palinski, W., S. Ylä-Herttuala, M. E. Rosenfeld, S. W. Butler, S. A. Socher, S. Parthasarathy, L. K. Curtiss, and J. L. Witztum. 1989. Antisera and monoclonal antibodies specific for epitopes generated during the oxidative modification of low density lipoprotein. Arteriosclerosis. 10:325-335

15. Rosenfeld, M. E., W. Palinski, S. Ylä-Herttuala, S. Butler, and J. L. Witztum. 1990. Distribution of oxidation specific lipid-protein adducts and apolipoprotein B in atherosclerotic lesions of varying severity from WHHL rabbits. Arteriosclerosis. 10:336-349.

16. Khoo, J. C., E. Miller, P. McLoughlin, and D. Steinberg. 1988. Enhanced macrophage uptake of low density lipoprotein after self-aggregation. Arteriosclerosis. 8:348-358.

17. Suits, A. G., A. Chait, M. Aviram, and J. W. Heinecke. 1989. Phagocytosis of aggregated lipoprotein by macrophages: low density lipoprotein receptor-dependent foam cell formation. Proc. Natl. Acad. Sci. USA. 86:2713-2717.

18. Berberian, P. A., M. W. Jenison, and V. Roddick. 1985. Arterial prostaglandins and lysosomal function during atherogenesis II. Isolated cells of diet-induced atherosclerotic aortas of rabbit. Exp. Mol. Pathol. 43:36-55.

19. Haley, N. J., H. Shio, and S. Fowler. 1977. Characterization of lipid-laden aortic cells from cholesterol-fed rabbits. I. Resolution of aortic cell populations by metrizamide density gradient centrifugation. Lab. Invest. 37:287-296.

20. Shio, H., N. J. Haley, and S. Fowler. 1979. Characterization of lipid-laden aortic cells from cholesterol-fed rabbits. III. Intracellular localization of cholesterol and cholesteryl-ester. Lab. Invest. 41:160-167.

21. Fowler, S., H. Shio, and N. J. Haley, 1979. Characterization of lipid-laden aortic cells from cholesterol-fed rabbits. IV. Investigation of macrophage-like properties of aortic cell populations. Lab. Invest. 41:372-378.

22. Fowler, S., P. A. Berberian, H. Shio, S. Goldfischer, and H. Wolinsky 1980. Characterization of cell populations isolated from aortas of rhesus monkeys with experimental atherosclerosis. Circ. Res. 46:520-530.

23. Tsukada, T., D. Tippens, D. Gordon, R. Ross, and A. M. Gown. 1987. HHF-35, A muscle-actin-specific monoclonal antibody. Am. J. Pathol. 126:5160.

24. Basu, S. K., J. L. Goldstein, R. G. W. Anderson, and M. S. Brown. 1976. Degradation of cationized low density lipoprotein and regulation of cholesterol metabolism in homozygous familial hypercholesterolemia fibroblasts. Proc. Natl. Acad. Sci. USA. 73:3178-3182.

25. Steinbrecher, U. P., S. Parthasarathy, D. S. Leake, J. L. Witztum, and D. Steinberg. 1984. Modification of low density lipoprotein by endothelial cells involves lipid peroxidation and degradation of low density lipoprotein phospholipids. Proc. Natl. Acad. Sci. USA. 83:3883-3887.

26. Salacinski, P. R. P., C. McLean, J. E. C. Sykes, V. V. Clement-Jones, and P. J. Lowry. 1981. Iodination of proteins, glycoproteins, and peptides using a solid-phase oxidizing agent, 1,3,4,6-tetrachloro-3,6-diphenyl glycouril (Iodogen). Anal. Biochem. 117:136-146.

27. Goldstein, J. L., S. K. Basu, and M. S. Brown. 1983. Receptor-mediated endocytosis of low density lipoprotein in cultured cells. Methods Enzymol. 98:241-260.

28. Lowry, O. H., N. J. Rosebrough, A. L. Farr, and R. J. Randall. 1951 Protein measurement with the Folin phenol reagent. J. Biol. Chem. 193:265-275.

29. Gamble, W., M. Vaughan, H. S. Kruth, and J. Avigan. 1978. Procedure for determination of free and total cholesterol in micro- or nanogram amounts suitable for studies with cultured cells. J. Lipid Res. 19:1068-1070.

30. Patton, S., and G. W. Kurtz. 1951. 2-Thiobarbituric acid as a reagent for detecting milk fat oxidation. J. Dairy Sci. 34:669-674. 
31. Haberland, M. E., D. Fong and L. Cheng. 1988. Malondialdehyde-altered protein occurs in atheroma of Watanabe heritable hyperlipemic rabbits. Science (Wash. DC). 241:215-218.

32. Boyd, H. C.. A. M. Gown, G. Wolfbauer, and A. Chait. 1989. Direct evidence for a protein recognized by a monoclonal antibody against oxidatively modified LDL in atherosclerotic lesions from Watanabe heritable hyperlipemic rabbit. Am. J. Pathol. 135:815-826.

33. Shaffner, T., K. Taylor, E. J. Bartucci, K. Fischer-Dzoga, J. H. Beeson, S. Glagov, and R. W. Wissler. 1980. Arterial foam cells exhibit distinctive immunologic and histochemical features of macrophages. Am. J. Pathol. 100:57-80.

34. Pitas, R. E., T. L. Innerarity, and R. W. Mahley. 1983. Foam cells in explants of atherosclerotic rabbit aortas have receptors for beta-very low density lipoproteins and modified low density lipoproteins. Arteriosclerosis. 3:2-12.

35. Jaakkola, O., O. Kallioniemi, and T. Nikkari. 1988. Lipoprotein uptake in primary cell cultures of rabbit atherosclerotic lesions: a fluorescence microscopic and flow cytometric study. Atherosclerosis. 69:257-268.

36. Jaakkola, O., S. Ylä-Herttuala, and T. Nikkari. 1989. Macrophage foam cells from human aortic fatty streaks take up $\beta$-VLDL and acetylated LDL in primary culture. Atherosclerosis. 79:173-182.

37. Van Lenten, B. J., A. M. Fogelman, M. M. Hokom, L. Benson, M. E. Haberland, and P. A. Edwards. 1983. Regulation of the uptake and degradation of $\beta$-very low density lipoprotein in human monocyte macrophages. J. Biol. Chem. 258:5151-5157.

38. Naito, M., M. Kuzuya, C. Funaki, Y. Nakayama, K. Asai, and F. Kuzuyu. 1987. Separation and characterization of macrophages and smooth muscle cells in rabbit atherosclerotic lesions. Artery. 14:266-282.

39. Koo, C., M. E. Wernette-Hammond, and T. L. Innerarity. 1986. Uptake of canine beta-very low density lipoproteins by mouse peritoneal macrophages is mediated by a low density lipoprotein receptor. J. Biol. Chem. 261:11194-11235.

40. Sparrow, C. P., S. Parthasarathy, and D. Steinberg. 1989. A macrophage receptor that recognizes oxidized low density lipoprotein but not acetylated low density lipoprotein. J. Biol. Chem. 264:2599-2604.

41. Mazzone, T., H. Gump, P. Diller, and G. S. Getz. 1987. Macrophage free cholesterol content regulates apolipoprotein E synthesis. J. Biol. Chem. 262:11657-11662.

42. Parthasarathy, S., M. T. Quinn, D. C. Schwenke, T. E. Carew, and D. Steinberg. 1989. Oxidative modification of beta-very low density lipoprotein potential role in monocyte recruitment and foam cell formation. Arteriosclerosis. 9:398-404.

43. Cathcart, M. K., D. W. Morel, L. J. Lewis, G. M. Chisolm III. 1985. Monocytes and neutrophils oxidize low density lipoprotein making it cytotoxic. J. Leuk. Biol. 38:341-350. 